\title{
ANALYSIS AND DESIGN MODIFICATIONS FOR UPGRADE OF STORAGE RING BUMP PULSE SYSTEM DRIVING THE INJECTION BUMP MAGNETS AT THE ALS*
}

\author{
Greg D. Stover \\ Advanced Light Source \\ Accelerator and Fusion Research Division \\ Lawrence Berkeley Laboratory \\ University of California \\ Berkeley, CA 94720
}

April 1995

Paper presented at the 1995 Particle Accelerator Conference

Dallas, TX, May 1-5, 1995

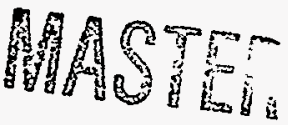

*This work was supported by the Director, Office of Energy Research, Office of Basic Energy Sciences, Materials Sciences Division, of the U.S. Department of Energy, under Contract No. DE-AC03-76SF00098. 


\section{DISCLAIMER}

This report was prepared as an account of work sponsored by an agency of the United States Government. Neither the United States Government nor any agency thereof, nor any of their employees, make any warranty, express or implied, or assumes any legal liability or responsibility for the accuracy, completeness, or usefulness of any information, apparatus, product, or process disclosed, or represents that its use would not infringe privately owned rights. Reference herein to any specific commercial product, process, or service by trade name, trademark, manufacturer, or otherwise does not necessarily constitute or imply its endorsement, recommendation, or favoring by the United States Government or any agency thereof. The views and opinions of authors expressed herein do not necessarily state or reflect those of the United States Government or any agency thereof. 


\section{DISCLAIMER}

Portions of this document may be illegible in electronic image products. Images are produced from the best available original document. 


\title{
ANALYSIS AND DESIGN MODIFICATIONS FOR UPGRADE OF STORAGE RING BUMP PULSE SYSTEM DRIVING THE INJECTION BUMP MAGNETS AT THE ALS*
}

\author{
G. D. Stover, Lawrence Berkeley Laboratory, University of California, Berkeley, CA 94720 USA
}

A fast (4.0 ms half period) resonant discharge pulse system, using SCRs, was designed and constructed to drive the injection bump magnet system at the Advanced Light Source (ALS)[1]. The commissioning process revealed a high frequency resonance ( $T=800 \mathrm{NS}$ ) superimposed on the driver discharge wave form. In addition, the peak amplitude of the magnet load recovery current exceeded design specifications. A SPICE analysis confirmed the suspected mechanisms for the parasitic ringing and the excessive load current "undershoot." This paper will address the subsequent analysis, measurements, and modifications carried out during the maintenance shutdown in June 1993.

\section{INTRODUCTION}

This paper will a short review the pulser electrical system design, and continue with a more extensive discussion of the problems discovered during commiss-ioning, the subsequent SPICE analysis of the system, the subsequent modifications made to the electrical system and finally the discuss the new wave forms measured more complete description of the injection process, the magnet layout and specifications and electrical system of the magnet drivers can be found in a previous paper.

\section{BASIC SYSTEM LAYOUT}

The sinusoidal current wave form required to drive the injection magnets is generated by the resonant discharge of a capacitor bank through a distributed array (64 total) of high voltage Silicon Controlled Rectifiers (SCRs) switches through a very low inductance transmission line (4 groups or 8 parallel cables) to the predominantly inductive magnet load. The basic topology for the pulse system is shown in Figure 1. The four parallel bipolar SCR-capacitor discharge modules that are shown in Figure 2.

\section{ORIGINAL MEASUREMENTS}

The bottom trace in Figure 3 is the output current from one of the four SCR pulse units.

\footnotetext{
*Work supported by the Director, Office of Energy Research, Office of Basic Energy Sciences, Material Sciences Division, U.S. Department of Energy, under Contract No. DE-AC03-76SF00098.
}

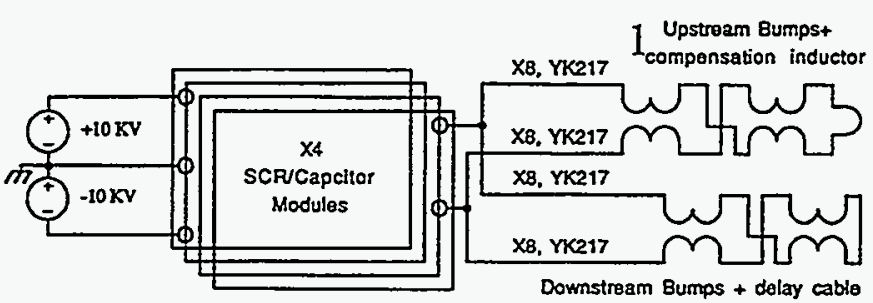

Figure 1. Bump puise system

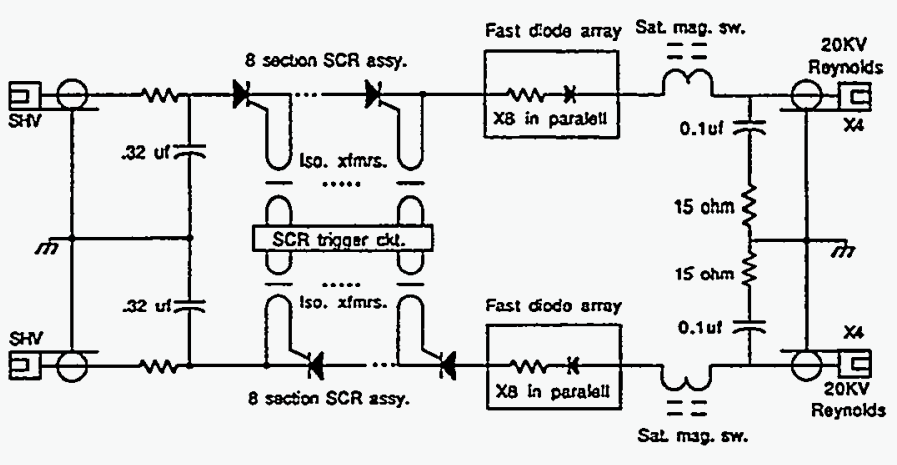

Figure 2: One of four bipolar SCR-capacitor discharge modules

The high frequency ringing superimposed on the discharge pulse has a nominal period of $800 \mathrm{~ns}$. Due to this parasitic ringing the peak $\mathrm{di} / \mathrm{dt}$ at the moment of turn-on has been measured as high as $3300 \mathrm{amps} / \mu \mathrm{s}$ over a period of 500 ns. This specification is more than twice the specified maximum listed for the SCR switches and was a potential source of damage. Additionally, as seen in figure 4 , the current in the magnet load rings negative to about $20 \%$ of the peak forward current. This value a 20 times larger than the $1.0 \%$ reverse ring specified for the injection bump magnets and could have adverse effects the smooth injection of stored beam. The distributed design of the pulse system prevented the iterative process of component substitution. A circuit analysis engine was adapted to solve the problem.

\section{A SPICE ANALYSIS}

A simplified model of the pulse system was developed using an Integrated Circuit Emulator (ISSPICE)[2]. The basic SPICE circuit is shown in figure 5. This simple circuit is a distillation of the major circuit elements of the pulse system: the series/parallel combination of the 16 energy storage 
capacitors (C1), the $64 \mathrm{SCR}$ switches (X1), the 8 antireversing diodes and saturating reactor switches (D1), the 32 coaxial cables (LOSSYLN, T1), and the magnet load (L1).

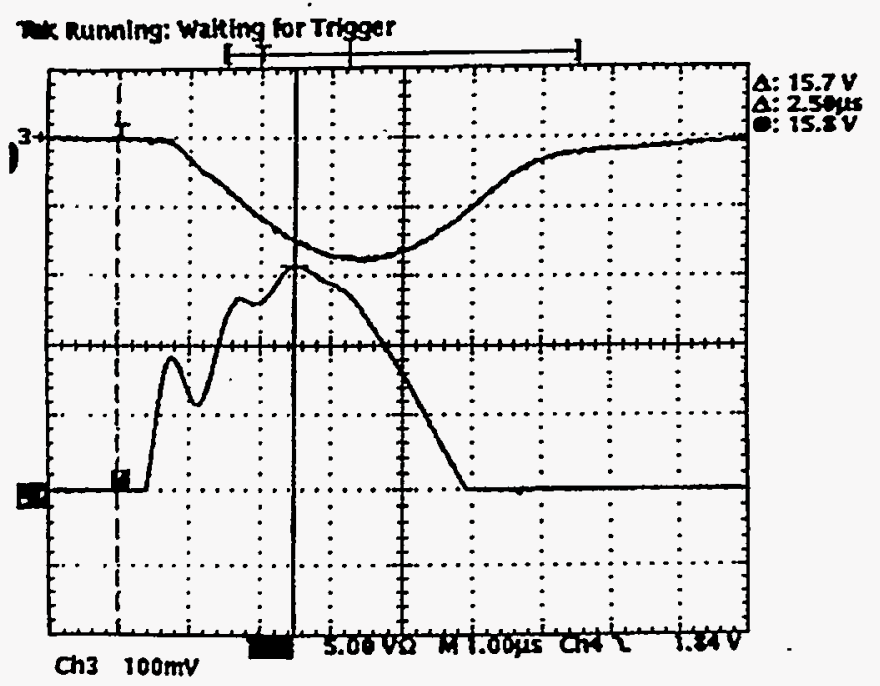

Figure 3: Magnetic field (upper trace, 666 gauss/div.) and pulser output current (lower trace, 500 amps /div.)

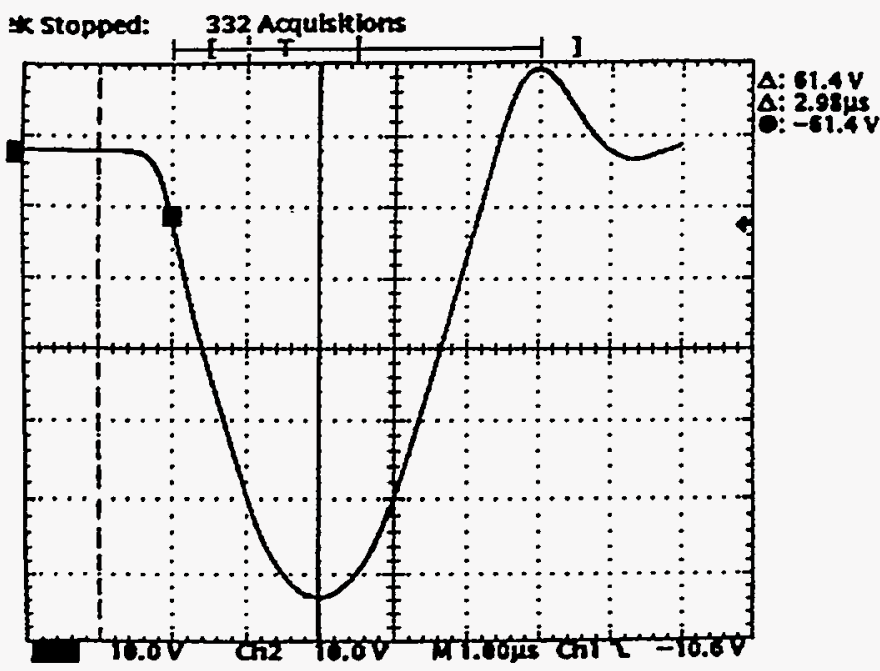

Figure 4: Magnet current wave forms (overlaid) in "upstream" and "downstream" bump magnets (100 amps/div.).

The lumped elements L2 and R5 represent the distributed inductance and resistance of the SCR switches. C2,3 and $\mathrm{R} 3,4$ represent the combined $\mathrm{RC}$ anti-ringing snubber circuits employed in the system. Circuit elements that have underlying complex sub circuit models include: LOSSYLN, $\mathrm{T} 1$ a distributed parameter lossy transmission line and voltage source PULSE, V5 which contains a switch control wave form that mimics the delay and nonlinear turn-on characteristics of the SCRs modeled by SWTTCH, XI.
The large well defined circuit elements $(R 2, C 1, D 1, T 1$, the snubbers and L1) were connected together adjusted until bulk characteristics of the simulator wave forms were in good agreement with measured system wave forms. By virtue of the complexity of the distributed pulse system the measurement or precise calculation of the parasitic components (esp. L3 and R5) would be very difficult and time consuming. As a consequence the parasitic components (L2, L3, R5, and V5) were added and empirically adjusted to mimic the measured wave forms in Figures 3 and 4 . As shown in Figure 6 the resultant model generates source and load wave forms that give reasonably good agreement in period, amplitude and general wave shape with the measured wave forms. The resultant circuit model strongly suggests a likely source of the high frequency parasitic oscillations.

The ringing is initiated by the initial turn-on transient created by unrestrained inrush of current (high $\mathrm{di} / \mathrm{dt}$ ) into the large shunt capacitance presented by array of low inductance (high capacitance) transmission cables. The exponentially decaying oscillations are the result of a parasitic resonance between the distributed parallel inductance of the SCR pulse units and the cable shunt capacitance. Changing the switch inductance (L3) or the number of cables will dramatically alter the frequency and amplitude of these oscillations.

A reasonable solution to the resonance problem is shown in Figure 7. The parasitic ringing on the pulser current (top trace) is almost completely eliminated and the magnet load current reverse recovery amplitude is within the $1 \%$ specification. This effect was brought about by halving the number of coaxial cables from 16 to 32 , thus lowering the cable input capacity and replacing the RC snubbers with resistors thereby considerable reducing the parasitic and bulk (undershoot) resonance effects. Further reducing the number of cables would decrease the ringing effects and the excessive $\mathrm{di} / \mathrm{dt}$ but conversely increase the period of the magnet current pulse beyond it's specified requirements. The magnitude of the $d \mathrm{~d} / \mathrm{dt}$ at the beginning of the pulse current wave form was moderately reduced and its duration, in excess of 1500 amps/us specification, was halved.

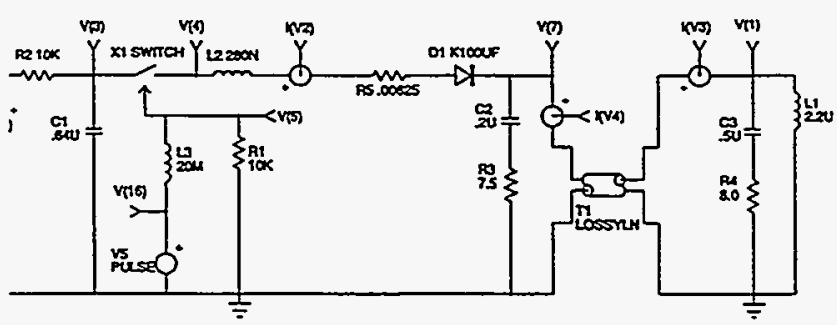

Figure 5: The basic SPICE circuit used in analysis of pulse circuit 


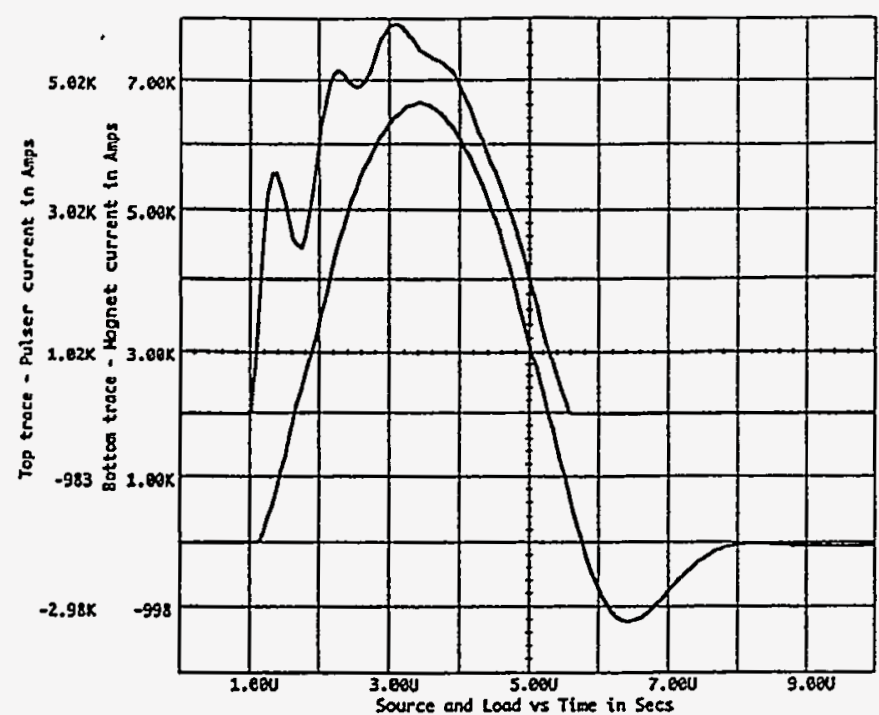

Figure. 6: SPICE model output wave forms before modifications: Pulser output current (upper trace, $1000 \mathrm{amps} / \mathrm{div}$.) and magnet load current (lower trace, $1000 \mathrm{amps} / \mathrm{div}$.):

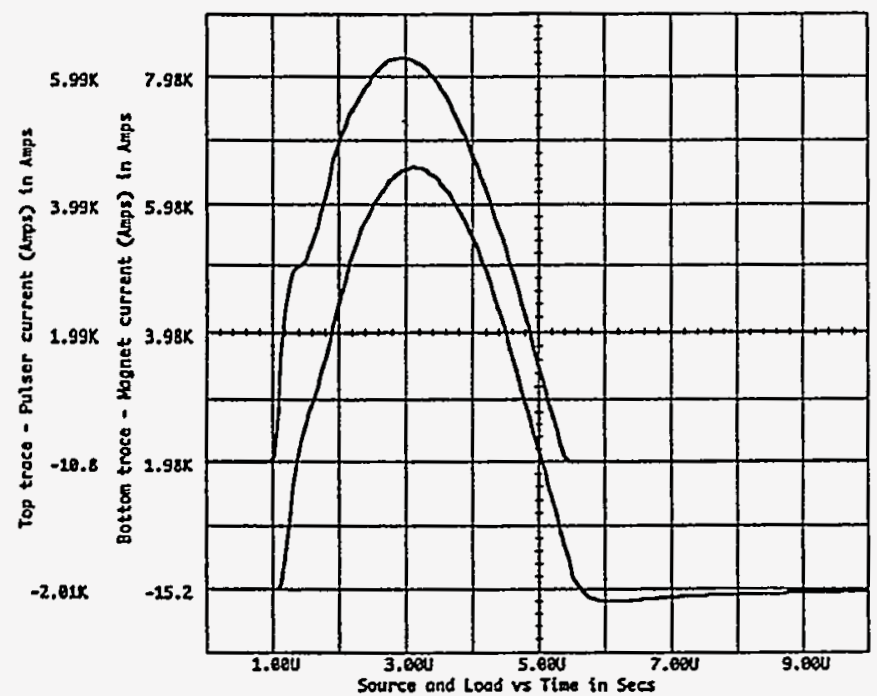

Figure 7: SPICE model output wave forms after modifications: Pulser output current (upper trace, $1000 \mathrm{amps} / \mathrm{div}$.) and magnet load current (lower trace, 1000 amps /div.).

\section{ACTUAL MODIFICATIONS AND RESULTS}

All the component values suggested by the SPICE models were applied to the Bump system. The number of coaxial cables was halved and the R-C snubbers were replaced by straight resistors. The resistor size was selected by power dissipation calculations obtained from the SPICE runs. As a protective measure, the core area of the saturating magnetic switches was doubled to further protect the SCR's from the remaining excessive $\mathrm{di} / \mathrm{dt}$. The correlation between the SPICE wave forms and the actual measured wave forms in Figures 8 and 9 is quite good.

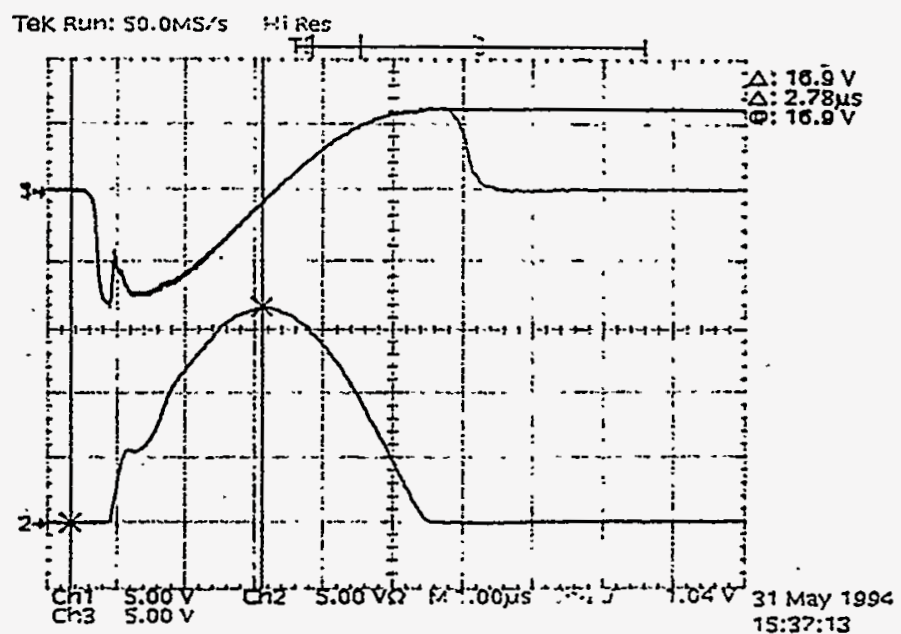

Figure 8: Actual pulse unit output current (lower trace 500 Amps./div).

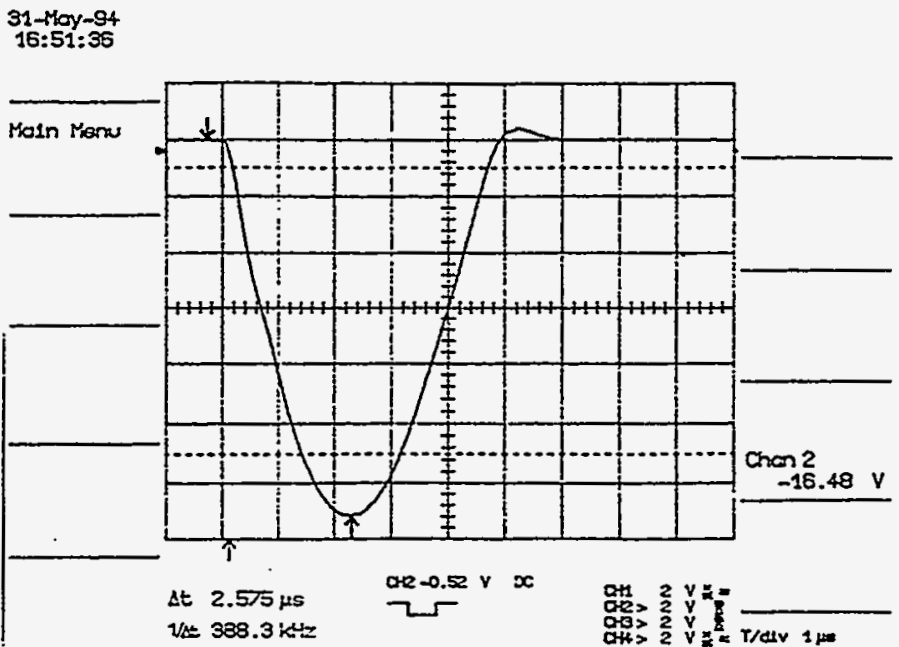

Figure 9: Actual magnet load current (1000 amps /div.).

\section{CONCLUSION}

A condensed and simplified SPICE model was been created to understand the mechanism of excessive $\mathrm{di} / \mathrm{dt}$, and parasitic ringing observed in the current wave forms of the recently constructed resonant discharge pulse system at the ALS. The SPICE model identified significant circuit problems and the appropriate corrections were made.

\section{REFERENCES}

[1] G. Stover, L. Reginato, "Analysis and Design Modifications for Upgrade of Storage Ring Pump Pulse System Driving the Injection Bump Magnets at the ALS", Proceedings of 1993 IEEE Particle Accelerator Conference, Washington, D.C., vol. 2, p. 1351-1353.

[2] Trademark of Intusoft, P.O. Box 710, San Pedro, CA 90733-0710, (310 833-0710. 